\title{
Contributing to Historical-Structural Injustice via Morally Wrong Acts
}

\author{
Jennifer M. Page ${ }^{1}$
}

Accepted: 22 October 2021 / Published online: 16 November 2021

(c) The Author(s) 2021

\begin{abstract}
Alasia Nuti's important recent book, Injustice and the Reproduction of History: Structural Inequalities, Gender and Redress (2019), makes many persuasive interventions. Nuti shows how structural injustice theory is enriched by being explicitly historical; in theorizing historical-structural injustice, she lays bare the mechanisms of how the injustices of history reproduce themselves. For Nuti, historical-structural patterns are not only shaped by habitual behaviors that are or appear to be morally permissible, but also by individual wrongdoing and wrongdoing by powerful group agents like states. In this article, I extend Nuti's rich analysis, focusing on two questions that arise from her theory of historical-structural injustice: (1) Beyond being blameworthy for wrongful acts themselves, are culpable wrongdoers blameworthy for contributing to structural injustice? (2) Does historical moral ignorance mitigate moral responsibility for past injustice? Regarding (1), I distinguish between the local and societal structural effects of wrongdoing. Though I think this distinction is wellfounded, it ultimately leads to tensions with structural injustice theory's idea of ordinary individuals being blameless for reproducing unjust structures. Regarding (2), I argue that even though it is natural for the question of historical moral ignorance to arise in considering past wrongdoing, at least in the case of powerful group agents, we should not overlook forms of cruelty which present-day moral concepts are not needed to condemn.
\end{abstract}

Keywords Structural injustice $\cdot$ Historical injustice $\cdot$ Alasia Nuti $\cdot$ Moral responsibility Blameworthiness $\cdot$ Wrongdoing $\cdot$ Moral ignorance $\cdot$ Cruelty

In August 2019, the U.S. Immigration Enforcement and Customs agency (ICE) launched a series of workplace raids aimed at deporting undocumented poultry plant workers in the U.S. South, most of whom were of Mexican or Central American origin. A swarm of ICE officials descended on the facilities in armed cars and with helicopters circulating, quickly escorting targeted workers into custody. A number were parents. Some were allowed to make childcare arrangements by telephone, and after a night or two, were released in order to be with their children until a future immigration hearing date. Others, including breastfeeding mothers, were separated on a longer-term basis (Gomez et al. 2019). President Trump may

Jennifer M. Page

jennifer.page@uzh.ch

1 Center for Ethics, Department of Philosophy, University of Zurich, Zurich, Switzerland 
have seen the raids as his Operation Wetback, which he had controversially praised as a candidate. The Eisenhower administration-led 1950s mass deportation effort aimed to rid the U.S. of "wetbacks" - a racist term referring to Mexican migrants who swam across the Rio Grande-based on the idea that illegal immigrants were to blame for unemployment and other social problems (Goodman 2020, Ch. 2).

A May 2020 viral video showed a white female dog owner calling the police on a black male birdwatcher, identifying him as African American and falsely claiming that he was threatening her. As she talks to the police, she adjusts her voice to make it increasingly frantic, creating the impression that the man was advancing and that an attack on her person was imminent. The birdwatcher had chided her for not leashing her dog in Central Park; given the prevalence of police killings of unarmed black men in the United States, her retribution literally put his life at risk. As many commentators observed, the video was notable not because it depicted anomalous behavior, but because the all-too-common trope was caught on video. The dog owner's actions fit in with a long history of white women using their social-epistemic credentials to fabricate stories of black male violence, knowing enslavers, sheriffs, and lynch mobs were ready to spring into action (Haines 2020).

Present-day workplace deportation raids and the Central Park 9-1-1 call are manifestations of "historical-structural injustice," the central concept of Alasia Nuti's Injustice and the Reproduction of History: Structural Inequalities, Gender and Redress (2019) — a book I admire deeply for its rigor, heart, and also for its originality as the first monograph in analytic political philosophy on history's structural and recurrent nature. ${ }^{1}$ Historical-structural injustice is the kind of injustice that is deeply embedded in the fabric of society. It is destined to keep happening because it is part of a long historical pattern, where only a radical disruption of societal norms would prevent its reproduction. It elicits the observation that history repeats itself. ${ }^{2}$

When we say that history repeats itself, this often is accompanied by moral condemnation; it is not a phrase used to call attention to continuities between, say, presentday triumphs and triumphs of bygone eras. Situations like the above-described ones feature conduct judged as morally wrong by, respectively, governments and individuals. Beyond the immediate victims in these cases, these are episodes that, on Nuti's theory, are taken up into the broader social structural ether, reproducing the norms which conduce the occurrence of events of their kind and contributing diffusely to harms to remote others (2019, esp. Ch. 3). For Nuti, they not only reproduce historical-structural patterns, they are also reproductions of the historical structural patterns that came before them.

This, however, is different from how structural injustice is often discussed in the philosophical literature. Iris Marion Young's (2011) highly influential theory of structural injustice is notable for its insistence that in situations where structural factors are prevalent, we should be less concerned with assigning blame and focus instead on transforming unjust structures. For Young, our behaviors are largely influenced by social forces that we had no part in creating; we just perpetuate these forces by uncritically doing what others around us do. An individual consumer of fast fashion in the U.S. is not blameworthy for abuses suffered by sweatshop laborers in Bangladesh, argues Young (2011, Ch. 5), though

\footnotetext{
1 Though as Daniel Butt observes in his contribution to this symposium, there are connections between Nuti's book and books by Spinner-Halev 2012 and Lu (2017), as each grapples with continuities between past and present injustice.

2 N.B. Nuti (2019, pp. 2-3) warns that "return-of-the-past narratives... in public discourse" often fail to "capture the complexity of the relation between past and present in thinking about justice.".
} 
he contributes, along with other fast fashion consumers, to creating the demand that fuels exploitative global labor practices.

Such a description of structural injustice focuses on behavior that is habitual and considered normal and acceptable. Oftentimes this behavior is, on evaluation, morally permissible. Take Nuti's example of occupational segregation, for which she present horizonal affirmative action-i.e., measures encouraging men to be schoolteachers and care workers, and women to be repairpersons and firefighters-as a policy remedy (2019, pp. 117-121, 145-150). Though one man's becoming an auto repairman or one woman's becoming a schoolteacher makes an (albeit minute) social structural contribution to occupational segregation, these are not morally impermissible choices. If we were morally prohibited from doing things that contribute in small ways to broader social structural forces that perpetuate injustice, this would frustrate a vast array of life projects that people are reasonable to have, setting the bar of morality implausibly high. This does not mean that all conventional behavior that contributes to structural injustice is morally permissible, but some of it clearly is. An individual who does something morally permissible is not blameworthy for that act, and would similarly not seem to be blameworthy for the act's contribution to structural injustice.

However, though an individual's making a gendered occupational choice seems morally permissible, perpetrating forms of intimate partner violence - another one of Nuti's (2019, pp. 106-117) central examples-is clearly not. Nor are the poultry facility deportation raids; nor is the white female dog owner's 9-1-1 call. How should we think about the blameworthiness of morally impermissible contributions to structural injustice? Though one of Nuti's many notable interventions is a theorization of social structural processes that acknowledges the role of both habitual collective behavior and wrongdoing with identifiable perpetrators, she is mainly interested in identifying powerful group agents like states as blameworthy. Her only explicit discussion of the blameworthiness of ordinary individuals concerns our failure to challenge historical-structural injustice. This article, then, is an attempt to fill in some of the gaps in Nuti's historical-structural injustice theory when it comes to blame and blameworthiness. I am primarily concerned with two questions that came up for me in reading Nuti's book. First, beyond being blameworthy for wrongful acts themselves, are culpable wrongdoers blameworthy for contributing to structural injustice? Second, we might think that present-day wrongdoers ought to be more morally knowledgeable than their historical predecessors, meaning that the Trump administration ought to be judged more harshly than the Eisenhower administration for deportation drives. Should this be the case on Nuti's theory of historical-structural injustice?

\section{Nuti on Historical-Structural Injustice}

Nuti (2019, p. 44) defines historical-structural injustice as "unjust social-structural processes enabling asymmetries between differently positioned persons, which started in the past and are reproduced in a different fashion, even if the original form of injustice may appear to have ended." She motivates her analysis as providing a corrective to the philosophical literature on historical injustice and reparations (2019, pp. 3-6). This literature tends to treat injustices like slavery as finite events that happened in the distant past, asking what, if anything, is owed to the descendants of enslaved persons. As Nuti conceives of the "historical" injustice of slavery, a long-term structural process began with the enslavement of black people; fueled by racist ideas, stereotypes, and social norms, it 
continued with segregation, convict leasing and other forms of criminalizing black bodies, reproductive injustices against black women, the suppression of black political power, mass incarceration, and so on. The resilience of the long-term structures that make up historicalstructural injustice owes to their ability to adapt and take on new forms as sociopolitical culture changes $(2019$, pp. 25-27).

According to Nuti, then, the idea of reparations for slavery misleadingly implies that enslavement was an isolated wrong conducted by temporally distant perpetrators with a different moral code than "us" today, when in fact, the forms of racism and racial violence in need of repair are still ongoing. Prescriptively, Nuti calls for intersectional, transformative, reparative structural justice that involves policy changes, more direct forms of reparations, and new historical narratives that emerge when we examine "the formal and informal institutions that regulate our societies... in order to understand the extent to which an unjust history still directs the workings of our institutions and is reproduced through them" (2019, p. 171).

Who, if anyone, is to blame for historical-structural injustice? Let us distinguish between:

(A) An action that causes harm only when lots of agents do the same action

(B) An action that would be harmful even if performed by a single agent in isolation

We can also distinguish between:

(1) A (first-order) action that is or is widely considered to be morally permissible which contributes to structural injustice

(2) The (second-order) effect of contributing to structural injustice via (1)

(3) A (first-order) action that is morally wrong which contributes to structural injustice

(4) The (second-order) effect of contributing to structural injustice via (3)

The focus of Young's well-known work on structural injustice is (A). She is interested in situations where the "actions of particular persons do not contribute to injustice for other persons directly... but rather indirectly, collectively, and cumulatively" (Young 2011, 96). That Young is moreover primarily interested in the structural effects of actions that are or appear morally permissible $(2,1)$ is clear from her critical discussion of the "liability model" of responsibility, which is applicable when one agent directly wrongs another. In thinking about social injustices like affordable housing shortages or climate change, there is a tendency for moral and political philosophers to expand the liability model's scopehere Young (2011, pp. 101-104) offers Christopher Kutz's (2000) work on complicity as an example. It is little wonder, observes Young, that such authors find individuals to be blameworthy for their participation; the liability model is uncritically assumed. She calls for another way of thinking about responsibility that is "more forward-looking than backwardlooking" (Young 2011, p. 108), emphasizing the moral obligation we all have to work to overcome structural injustices, regardless of our role in creating them. Young does not deny that sometimes morally wrong actions contribute to structural injustices, but argues for individuals to focus on social change rather than looking to assign blame.

It should be emphasized that wrongful acts are not and cannot be structural injustices themselves: Structural injustices "are analytically distinct" from wrongdoing "that can be only attributed to states and/or powerful institutions" and "wrongs only inflicted by blameworthy interactions," as Nuti $(2018$, p. 209) puts the point. But at the same time, as Nuti (2019, esp. Chs. 3-4) demonstrates, many forms of wrongdoing would 
be misunderstood without taking into account their historical-structural context. We would miss both the complex origin of the wrongful act, one that is much broader than what a single perpetrator chose to do, as well as the way in which the act reproduces and perpetuates the social structural forces that contextualize it.

Accordingly, while Nuti acknowledges her debt to Young as the leading proponent of structural injustice theory, she questions her strong normative commitment to forwardlookingness, challenging Young for neglecting (B) and $(3,4)$, especially in the case of powerful group agents like states $\left(2019\right.$, p. 186). ${ }^{3}$ Nuti's alternative account of structural injustice, then, not only highlights the role of history, but also carves out a space for assigning blame. Powerful group agents owe reparations based on a distinctively backwardlooking "structural debt" that has "accumulated over time through their actions (and inactions) within unjust structures" (2019, p. 157). Actions and policies that contribute to structural debts are oftentimes morally impermissible. Nuti illustrates the concept with the history of reproductive injustice against black women in the United States, a history that includes the sexual violence that accompanied legal, constitutionally-protected slavery in the nineteenth century and eugenic sterilization laws in the twentieth century (2019, pp. 157-160). It is wrong, on Nuti's view, to conceive of structural injustice in a way that downplays the formative role of states and other powerful group agents in shaping and reinforcing unjust social structures via morally wrong actions and policies.

What, then, of the blameworthiness of ordinary agents on Nuti's theory of historicalstructural injustice? Nuti's social ontology sees structural injustice as sustained not only by the actions of powerful group agents, but through both the morally permissible and impermissible practices of ordinary individual agents. Yet in considering questions of blame in her final chapter and conclusion, Nuti's concern is with the more Youngian subject of whether individuals are "morally responsible and blameworthy for their failure to address structural injustice" (2019, p. 189, my emphases). Her answer is that ordinary individuals are not blameworthy, though they may be criticized if they derive privileges from unjust structures and do nothing. But what about the perpetrators of, for example, intimate partner violence, which would be wrong even if it did not contribute to broader structures of gender injustice? Are they blameworthy for the structural effects of their actions, and would blameworthiness mean that perpetrators of intimate partner violence have special responsibilities to work to overcome gender injustice like states do? Nuti briefly tells us that we should

avoid conceiving of ordinary individuals' political responsibility as a responsibility that everyone shares in virtue of their contribution to structural injustice. In other words, we should distinguish between (1) the sociological analysis of how structures are sustained and reproduced over time (i.e., through individuals' exercise of their agency) and (2) considerations of responsibility and criticism. Position within unjust structures, rather than (1), should be the main basis for (2) (2019, p. 189).

Admittedly, Nuti tells us that this is a line of analysis that "she cannot fully explore" (2019, p. 189): A thoroughgoing defense of this position is not undertaken. But I wonder how committed she would be to it if pressed. This is the task I'll take up next.

\footnotetext{
3 The specification that powerful group agents are of interest is important; church choirs and running clubs do not impact structural injustice the way states and large corporations do.
} 


\section{Blaming Wrongdoers for Contributing to Structural Injustice?}

For Nuti (2019, p. 190), ordinary individuals who are in a privileged position "vis-àvis certain unjust structures should be politically responsible for their eradication"; this is preferable to saying that individuals should work to eradicate historical-structural injustice because they are on the hook for contributing to it. (Again, Nuti only wants to put powerful group agents on the hook in this way.) Like Nuti, I've long accepted that ordinary individuals whose routine, socially-accepted behaviors reproduce unjust structures are not blameworthy. But what about morally wrong actions by blameworthy individual perpetrators that contribute to the reproduction of history?

As Nuti's analysis makes clear, how historical-structural injustice is reproduced is extremely complex. There could never be a ledger with enough detail to capture every single interaction that causally contributes to a given form of structural injustice. It seems to fit the nature of structural injustice to say that individuals' duties to transform unjust structures are primarily forward-looking.

However, reflecting on the futility of a structural injustice ledger implicitly assumes that we are considering structural injustice at the level of human society in the abstract. Insofar as individuals contribute to the formation and reinforcement of societal-level social structures, it is via an influence on their more immediate environments- their households, workplaces, neighborhoods, and so on. Consider an act of sexual harassment carried out by a male boss who oversees thousands of employees and has the power to shape the culture at his firm. It seems uncontroversial to say that sexual harassment by the boss impacts the firm's social structural milieu by normalizing sexually aggressive workplace behavior by male employees. I don't see why we shouldn't call explicit attention to both the blameworthiness of the boss for the act of sexual harassment and the structural effects of his actions at the firm. Indeed, in practice, blaming a boss for perpetuating a sexist workplace culture is a familiar enough idea. If we're comfortable blaming the boss for the local structural effects of his actions, then it seems logical that he would have special reparative duties regarding these effects, in addition to his first-order reparative duties to the immediate victims of his harassment. Here, based on his causal contribution, the boss has a special backward-looking duty to work to transform structural gender injustice at his firm-a duty that moreover seems weightier than the forward-looking duties of individuals who are privileged in the gender injustice context.

But here's where things get complicated. Suppose that the boss has the special reparative duties that I've described, and suppose that he fulfills them. The Me Too movement, say, makes him more reflective about his own sexism, and he actively participates in a variety of concrete measures aimed at ending the firm's misogynistic culture. ${ }^{4}$ In doing this, the boss would also seem to contribute to overcoming structural gender injustice at the level

\footnotetext{
${ }^{4}$ N.B. Even if a person has special reparative duties, discharging them may come with the risk of doing further harm. Think about a male domestic abuser who, having forsworn future violence, attempts to repair the broader unjust gender dynamics in the household where he lives with his female partner and their children. She may just want him to leave. Even with the boss, it is not clear that he has the moral standing to be involved in repairing the culture at his workplace. He might be so distrusted that even a best-case effort where his victims and other female employees are invited to be involved as active participants (Nuti 2019, pp. 166-171) in a cultural overhaul at the firm backfires. It may be best for him to simply resign and cut off ties, leaving the work of transforming the firm's culture to a successor or persons specifically hired for this purpose. I'm not sure where this set of considerations pushes us in terms of the four options I outline for Nuti (if anywhere).
} 
of human society, however invisibly compared to the much more perceptible local impact of his actions. The question, then, is how to think about the boss's societal-level contribution to overcoming structural gender injustice. In fulfilling his backward-looking duty in the local context, is he fulfilling a forward-looking duty—one that he equally shares with all other genderprivileged persons - at the societal level? Alternatively, is his societal-level duty structured in the same backward-looking way as his local duty, a reparative duty that arises because of the structural effects of his morally wrong actions? But if the latter is the case, then it seems that we shouldn't only think about ordinary individuals' responsibility for transforming unjust social structures as grounded in shared forward-looking duties, but also as sometimes grounded in duties of reparation that vary from individual to individual. Is this right?

I can think of four ways that Nuti could respond, though each way seems to have drawbacks:

Expanding "powerful agents" to include individuals like the sexist boss. For Nuti, powerful group agents like states incur blame for their causal contributions to historicalstructural injustice. Perhaps the reason why the sexist boss seems blameworthy for the structural effects of his actions is his power; what he does makes a perceptible difference at his firm, just as states make a perceptible difference in the societies they operate in. However, power is contextual and relational. What about a worker who's powerless in his occupational capacity but influential within a small circle of male friends whose catcalling reinforces the misogynistic ethos of the group: Would he have backward-looking duties to transform the culture of his group of friends? Or would his duties be forward-looking? Where do we draw the line to say who has enough power, and where, such that they're on the hook for the structural effects of their actions?

Denying that wrongdoers are to blame for / have special duties to repair the structural effects of their actions. Perhaps it is true that we can identify the structural effects of the boss's actions at the firm, but taking the structural nature of our social reality seriously, surely his actions have diffuse structural effects elsewhere as well; a firm is not a self-contained whole that feeds its structural inputs directly into the broader social ether. It seems a bit ridiculous to try to figure out all the structural effects of our wrong actions, let alone saying that we have reparative duties based on them. The way I have been describing the structural effects of actions might reinforce the very individualism that forward-looking models seek to avoid. Nevertheless, this seems to miss what I take as being the point of assigning special reparative duties to the boss. Imagine the firm successfully transformed its culture and the news media reported on this, referencing the boss's role in the cultural overhaul but not considering it important to mention his history of sexual harassment. Women at the firm might reasonably come forward and say, "You're acting like what this guy did was a gift, but really, he owed it to us because he was the worst sexist of all" (see McGary 1999, pp. 116-117). To use another example, I once knew a guy who convened a group modeled on Alcoholics Anonymous for men in the punk/hardcore scene who had committed sexual violence. If members of the group attended a Women's Strike demonstration, in the eyes of those in their circles and those they've hurt, it would seem to matter that they're there trying to repair some of the structural effects of the harms they've perpetrated rather than attending simply as gender-privileged persons like any others.

Biting the bullet and saying that responsibility to transform historical-structural injustice can derive from reparative duties of individuals whose blameworthy actions have structural effects. Maybe, then, ordinary individuals' duties to transform historical- 
structural injustice don't only stem from their structural position; perhaps some individuals have reparative duties vis-à-vis historical-structural injustice (Sangiovanni 2018). I wonder, though, where we draw the line between who has reparative duties and who doesn't. Only individuals whose wrongful actions violate established moral/legal norms? What about when wrongful conduct is normalized by mainstream morality? Should we go as far as to accept, as some authors (e.g., Hiller 2011; Butt 2013; Lawson 2013; Zoller 2015; Sangiovanni 2018) have claimed, that sometimes our ordinary, everyday contributions to large-scale collective harms are culpable, which would mean that our duties to transform unjust structures have a backward-looking dimension? ${ }^{5}$ Would this cede too much to liability models of responsibility?

Limiting the scope of special reparative duties to the local structural effects of wrongful actions. If we worry about the implications of individuals' having reparative duties visà-vis societal-level structural injustice, perhaps we could say that only the local structural effects of wrongdoing generate special reparative duties. However, this would still mean that we're characterizing the perpetrator of sexual violence who attends a Women's Strike demonstration as someone who's there based on his gender privilege rather than as someone owing a reparative duty. (I am assuming that the point of attending gender justice rallies is to fight societal-level structural injustice, and not just localized structural injustice.) Also, how do we distinguish between local and non-local structural effects? Suppose the sexist boss works in tech: his sexism has had structural effects within the tech sector, but also his firm's reckoning with gender injustice influences other firms to undertake similar efforts. There's something attractive about saying that the boss has wide-ranging reparative duties for the structural effects of his actions, which he ought to concentrate on discharging locally, but that doing so satisfies his non-local duties, e.g., in his industry, in society. However, this picture suggests that the boss's non-local duties are reparative in nature; otherwise, at one point does a reparative duty transform into a forward-looking one?

Of these four routes (and perhaps there are others I've not thought of), is there one that's attractive? How should the drawbacks be dealt with? I'm interested to hear Nuti's thoughts.

Keeping with the general theme of assessing blameworthiness within a historicalstructural injustice framework - admittedly, that's about it for a connection-let's turn to our other topic.

\section{Past Injustice, Moral Ignorance, and the Blameworthiness of the Historical State}

So far we've considered whether the structural effects of individual wrongdoers' actions are culpable and generate reparative duties. That agents are blameworthy for the wrongful actions themselves has been a background assumption. But an act of sexual harassment could be wrong without an agent being blameworthy for it. If a man lives in a time where sexist

\footnotetext{
5 See also Lawford-Smith (2012), who argues for the political efficacy of framing individuals' duties in reparative terms; by contrast, Darby and Branscombe (2014), argue that blame is politically inefficacious.
} 
language is so common that he participates in its usage without realizing that it's offensive and harmful, his actions may not be culpable.

Does belonging to a historical era where something we now know to be wrong was widely accepted undercut blameworthiness? While the historical sexist has been a much-debated figure (e.g., Calhoun 1989; Rosen 2003; Harman 2011; Mason 2015), to my knowledge, the blameworthiness of historical powerful group agents, especially historical states, is a topic that has not received explicit attention in the literature. It is also the most important topic for Nuti's analysis, as the state is the main actor whom she focuses on as bearing reparative responsibilities. Since Nuti doesn't consider whether the historical state's blameworthiness would be potentially mitigated by moral ignorance, I will consider the question here. As I will argue, though it might be tempting to characterize the historical state's moral ignorance as "active," rendering the state culpable, it's more accurate to say that in many cases, the historical state's wrongs were not done in ignorance at all. This, I think, would be the right response for Nuti to critics who would press her on the issue.

How would historical moral ignorance potentially mitigate blameworthiness? According to dominant philosophical views of moral responsibility, blameworthiness requires morally responsible agency, which itself requires meeting a control condition and a knowledge condition. The control condition stipulates that a responsible agent's actions are not the result of external coercion, but are freely undertaken. This condition does not seem to be affected by passage-of-time-related considerations, but the knowledge condition may be. For the knowledge condition to be satisfied, wrongdoers must be able to know what they're doing is wrong. But if they belonged to a historical era where dominant notions of right and wrong around gender, race, ability, etc., were systemically in error, the knowledge condition does not seem to be met.

On Moody-Adams's (1997, p. 69, 91 et passim) analysis, however, what matters morally is not what an agent knows, but what knowledge is available to an agent. She describes the tendency to treat the cultures of past eras as monoliths, something which fuels a relativistic unwillingness to condemn past injustices. However, she argues, dissenting voices and alternative points of view can always be found among those who suffered injustice. Similarly, Medina (2013, p. 99) cautions: "We should be careful not to tie too closely people's hermeneutical capacities to the repertoire of readily available terms and coined concepts, as if oppressed subjects did not have ways of expressing their suffering." Dissenting voices provide an opening for present-day persons to express non-anachronistic moral condemnations of past injustice, and to say that past agents were blameworthy. For Moody-Adams, the ignorance that might appear to present-day persons as genuine is actually affected.

Moody-Adam's concept of affected ignorance isn't entirely satisfying; it suggests that agents are deliberately constructing their situation of ignorance, the way a CEO says, "bring me the profits, don't tell me how you got them" (Mason 2015, p. 3041). A more fitting description is what Medina (2013, p. 39) calls "active" ignorance resulting from the epistemic vices of "arrogance, laziness, and close-mindedness." Active ignorance is culpable, Medina (2013) argues, since agents are morally responsible for keeping their epistemic vices in check (see also FitzPatrick 2008; Sher 2009). And so, as a basis for a structural injustice theorist to respond to the historical moral ignorance challenge, active ignorance seems promising. Indeed, the concept implicitly appears in Nuti's (2019, p. 174) discussion of Mills's (2007) essay "White Ignorance." Yes, according to Nuti and Mills, white Americans are ignorant "of the past wrongs committed against African Americans and the contributions African Americans made to American history and society over time," but this is because historical memory is structured to uphold "the idea of white superiority" (Nuti 2019, p. 174). 
It makes sense, in my view, to consider the phenomenon of active ignorance when it comes to the epistemic vices of groups like white Americans or of individual group members. But this doesn't automatically translate into the idea of the state being actively ignorant in all contexts, even when it's the members of this group who populate the ranks of government. ${ }^{6}$ When state policies are sufficiently intentional, ignorance is the wrong paradigm. ${ }^{7}$

To see this, let us return to our original example of deportation in the United States. One of the hallmarks of structural injustice is that there are not simplistic binaries between victims and perpetrators (Nuti 2019, p. 113; Young 2011, p. 116; Lu 2017, p. 162); this aptly describes the political context of the Eisenhower administration's deportation drives. Mexican American civil rights groups "withheld extensive criticism" as mass deportations were being arranged (Office of the Historian 2013, p. 338). Senator Dennis Chávez, the Senate's first Hispanic member, championed a permanent Fair Employment Practices Commission to protect Hispanic laborers from racial discrimination (Office of the Historian 2013, pp. 334-335), yet spoke disparagingly of the "wetback" situation and advocated harsh measures in Congressional debate on the subject ("Prevention of Illegal Entry of Aliens" 1952, p. 795). While some of Chávez's colleagues worried that Mexican migrant workers were susceptible to exploitation by employers, who were quick to threaten deportation if the workers protested low wages and harsh conditions, others candidly expressed nativist viewpoints, e.g., "There are hundreds of thousands of wetbacks in this country literally adulterating the American employment market and posing great social and legal problems to the people of the United States" ("Prevention of Illegal Entry of Aliens" 1952, pp. 793-794).

However, though structural injustice was the backdrop to the Mexican migrants' situation, and though surely many individuals were actively ignorant, the U.S. government's actions in Operation Wetback were not the unfortunate, inevitable product of broader social structural forces, nor does ignorance appropriately characterize these actions. Complex factors were indeed at play in the U.S. government's decision to intervene in the migrant labor situation, but what the government ended up doing was simple from a moral standpoint. Though U.S. employers seeking low-wage labor actively solicited illegal border crossings by Mexican migrants, when the economic tides changed and U.S. citizens began blaming the migrants for unemployment, instead of penalizing the employers, indiscriminate, harried purges were the response, often separating families and leaving migrants little or no time to gather their possessions. "Repatriation" journeys were characterized by their brutality, designed to impose enough suffering so as to discourage future unauthorized border crossings (Goodman 2020, Chs. 2-3). In short, the U.S. economy relied on cheap migrant labor when this was perceived as beneficial, but once it no longer was, the government expelled the migrants in inhumane ways: Their persons, and the lives they built in the U.S., were expendable.

A historical-structural perspective helps us think through the government's epistemic situation as the perpetrator of the deportation drives. Consider again the idea of Trump-era

\footnotetext{
${ }^{6}$ Notably, Mills (2017, pp. 65-67) underscores the state's role in promoting active ignorance; the state's promoting active ignorance is not done in ignorance, but with full knowledge.

7 N.B. I assume that ignorance does matter in assessing blameworthiness when policies aren't sufficiently intentional. To use one of Nuti's (2019, pp. 2019, p. 187) examples, if UK austerity policies weren't intended to promote intimate partner violence, this could be genuine or active ignorance (depending on whether the knowledge of this potential consequence was "out there" or not), and the UK's actions are less culpable than in a case where it knowingly undertook policies that promoted intimate partner violence. Of course, it may be unsatisfying that I use the terminology of "sufficiently" intentional, as if there is a bright red line that's crossed or not. What is that line? But this problem applies to all moral responsibility theorizing where it matters normatively that actions are intentional.
} 
deportations as structural reproductions of Operation Wetback and other deportation drives of the mid-twentieth century. Commonalities included the disregard of family ties, the lack of procedural fairness, work migrants being punished rather than employers-actions inseparable from nativism and anti-Latino racism. It doesn't seem fitting to charge the U.S. government of Trump with moral ignorance, cruel as its actions were. Likewise, when looking at the U.S. government of Eisenhower, we should not lose sight of the cruelty in asking ourselves if it could have known better. That it is wrong to treat others cruelly is so morally basic, so universal in its reach, it is reasonable to assume that it could have. In warning against a morally relativistic approach to historical cruelty, Nomy Arpaly and Timothy Schroeder (2014, p. 182) use the example of an ancient Roman who goes to the colosseum to see people being devoured by lions: "Enjoying other people's suffering in this manner speaks ill of the agent's will even if the enjoyment in question is encouraged by a corrupt and corrupting society, and even if there is no moral theory available that disagrees." Cruelty is sometimes associated with taking pleasure in another's pain, and from this perspective, any witness to an injustice can show a cruel nature in the manner of the colosseum spectator. But it is all the more vicious to carry out cruelties, to inflict "pain upon a weaker person or group.... in order to achieve some end, tangible or intangible, of the latter," in Shklar's formulation (1998, p. 11). Though our temporal distance may lead us to think that historical perpetrators were in a moral-epistemic haze that has thankfully been lifted, and that provides at least a partial excuse for their cruel conduct, this portrayal should be resisted.

When a group agent like a state perpetrates cruelties, some of its members may be indeed morally ignorant. Consider a college fraternity where brutal hazing rituals are the norm. Things are taken too far, punishments are considered, and one member says, in earnest, that he got so caught up in things that he lost sight of right and wrong. A victim of the hazing practices might be satisfied to hear the admission that there was a kind of groupthink happening; it seems plausible as a description of what happened. Moral ignorance of this kind may, depending on the circumstances, exculpate an individual frat member a bit, more so if he was a new, low-ranking member, not a ringleader, et cetera. However, once we move from the individual members of the fraternity to the fraternity qua group agent, the plea of moral ignorance would not seem to carry any normative weight at all. If groupthink was fostering moral ignorance, this gives us all the more reason to focus on the blameworthiness of the group itself, in addition to evaluating the members on an individual-by-individual basis (List and Pettit 2011, Ch. 7). Here, the fraternity would seem culpable for cruel practices plain and simple.

Accordingly, some individual officials employed by the Immigration and Naturalization Service (INS) agency who carried out Operation Wetback and similar deportation drives might have been morally ignorant in the manner of the fraternity members. However, moral ignorance does not let INS or the U.S. government qua group agents off the hook: What the government did was unmistakably cruel, and it didn't have to be that way. As a mother, Maria Fernanda Prieto, was taken into custody for deportation in 1942, she told immigration officials of her three-year-old daughter and also asked for some of her clothes - "a request that I honestly never thought they were going to reject on humanitarian grounds." But she was wrong, and wrote to Mexican officials that "neither my first efforts, nor my later begging, no prayers while they carried out my deportation had the slightest effect" (Goodman 2020, p. 51). One Texas resident complained to the U.S. attorney general's office in 1953: "I have seen mothers deport[ed] and leave on this side their nursing babies... What is the matter with this country anyway?" (Goodman 2020, p. 51). A Mexican girl was separated from her father when their family was 
deported from their Indiana home: "This is my country but after the way we have been treated I hope to never see it again... As long as my father was working and spending his money in Gary stored, paying taxes and supporting us, it was all right, but now we have found that we can't get justice here" (Balderrama and Rodríguez 2006, p. 131). "Operation Wetback was not a campaign grounded in hearings, formal proceedings, and the airing of Mexicans' cases and rights; it was mass deportation on the cheap, by whatever means necessary," as one historian puts the point (Goodman 2020, p. 66).

Why was Operation Wetback so cruel? Though there are surely many reasons, perhaps one answer has to do with the nature of state power itself. It is commonplace that in politics, moral considerations are not dispositive; the political realm is the realm of dirty hands. We punish political candidates for being too idealistic. One of the reasons Michael Dukakis is believed to have lost the 1988 U.S. presidential election is his answer to a debate question about whether he'd support the death penalty if his wife, Kitty, were raped and murdered-he straightforwardly said that he's opposed the death penalty his whole life. From the perspective of swing voters, Dukakis's clinging to his ideals in answering this question represented someone who was unable to handle the tough choices and tradeoffs that a president often has to make.

Philosophical work on politics and dirty hands often considers circumstances where, morally, the ends very well may justify the means. Sometimes there are decisions needing to be made where all the options are unsavory in some respect, and it falls on political leaders to sully themselves while allowing citizens to maintain a self-image of moral innocence (Walzer 1973; Thompson 1987). But many state-sponsored injustices aren't like this. Some of the things states do are just wrong; as I want to suggest, this is because of the nature of the political realm itself. The state is not the kind of entity we expect to be guided by moral considerations first and foremost. "Public cruelty... is made possible by differences in public power," as Shklar (1998, p. 11) writes, "and it is almost always built into the system of coercion upon which all governments have to rely to fulfill their essential functions." Shklar's insight is on stark display when power differences between white insiders and non-white outsiders enable the state's cruel treatment of the latter. Many of the injustices committed by states arise from the usual immoralism, race-based and otherwise, that characterizes politics.

Of course, political officeholders sometimes do factor moral considerations into their deliberations. In group agency theory, though, what group agents do is not determined by every member acting in a unified way. The internal decision structures of group agents are intricate, and individual members may operate on different, competing, and contradictory motives. There may be times when the rationality of the group agent as a whole is non-reducible to the rationality of individual group members, as List and Pettit's (2011, pp. 43-47) discussion of the discursive dilemma shows. Accordingly, that some officeholders are sometimes morally motivated does not rebut political immorality as a general idea. Moreover, I am not arguing that all state actions are immoral. Rather, my claim is that when there are immoral state actions, this will often be due to immoralism itself rather than moral ignorance. When it seems like there is a ruthless realpolitik logic at work in a state's operations, as in the case of Operation Wetback and other deportation drives of that era, we should take this at face value.

However, is it possible for the concept of moral ignorance to encompass the kind of political immoralism I've described? If there is an attitude that moral considerations do not apply in the political realm, but in fact they do, isn't this a kind of moral 
ignorance ${ }^{8}$ Though this may be true, this is different from the more philosophically challenging kind of moral ignorance where an agent, having thought about the matter at length, determines, say, that one's only moral duty as a business owner is to maximize the shareholders' profits by all means possible, since no-holds-barred economic competition best promotes human flourishing (Rosen 2004; FitzPatrick 2008; Harman 2011). Here, the business owner fulfills their procedural obligations to be morally introspective about one's actions but arrives at the wrong moral conclusion: are they fully blameworthy? By contrast, I am interested in the context where there is no moral introspection; the procedural obligations aren't fulfilled. This kind of moral ignorance is so clearly culpable, I think, that in our real-world blaming practices, it usually doesn't emerge as something under consideration for possibly undercutting moral responsibility.

A final issue arises from how I've interpreted the wrongness of mid-twentieth century deportation drives. What about the injustice of closed borders? The problematic nature of law and order-based solutions to problems rooted in social inequality? Shouldn't such things factor into an analysis of why deportation drives are wrong, and if so, aren't conversations around them much more recent? However, the moral reasons against a given wrong are often overdetermined. That punitive methods of controlling social inequalitydriven behaviors are morally problematic (and so on) provides an additional reason not to conduct Operation Wetback-style deportations, but much more basic moral prohibitions against cruelty are sufficient for understanding their wrongness. Furthermore, though moral ideas around open borders, the wrongness of overcriminalization, and anti-racism are increasingly part of today's sociopolitical climate on the left, these are not the only kinds of ideas that illuminate why deportation drives are wrong. Moral prohibitions against cruelty can be found in religious teachings, and people today are a lot less religious than they used to be-in the early 1950s, only $1 \%$ of U.S. Americans identified as non-religious compared to $21 \%$ today ("Religion" 2020). I am not convinced, in other words, that the present-day U.S. left has privileged epistemic access to being able to see the deportation drives as wrong. Rather, some of the reasons for morally opposing deportation that people today have access to may be different than the reasons that were widely accessible in previous eras. In my view, the Eisenhower administration was acting on the same kind of political immoralism that is apparent in the actions of the Trump administration in treating migrant workers with an easily-condemnable cruelty. The two administrations would seem to be equally blameworthy.

This Injustice and the Reproduction of History response article began with two examples of historical-structural injustice manifesting itself. Besides the Trump administration's deportation raids, what about the other example, the white female dog owner fabricating an attack by a black man in her 9-1-1 call? Is she more blameworthy than her nineteenth and twentieth century counterparts due to changed moral understandings-in the twenty-first century, perhaps ignorance of the moral wrongness of racial violence is less of an excuse? This gets into the question of individual blameworthiness as opposed to the blameworthiness of the state. However, perhaps the point about the active ignorance paradigm not applying to intentionally-committed cruel acts still holds. For the historical white women who falsely claimed to be victimized by African American men, there would be no incentive to give false testimony if one did not know its consequence, the imposition of the risk of physical harm or death. Unless there are other mitigating circumstances (e.g., suffering from a mental health condition), such an agent knows exactly what she is doing. Whether in the case of

$\overline{{ }^{8} \text { List and Pettit (2011, pp. 25-26 }}$ et passim) theorize group agent attitudes. 
individuals or states, one of the great drivers of immoralism is the knowledge that one wields disproportionate power.

Funding Open access funding provided by University of Zurich

Open Access This article is licensed under a Creative Commons Attribution 4.0 International License, which permits use, sharing, adaptation, distribution and reproduction in any medium or format, as long as you give appropriate credit to the original author(s) and the source, provide a link to the Creative Commons licence, and indicate if changes were made. The images or other third party material in this article are included in the article's Creative Commons licence, unless indicated otherwise in a credit line to the material. If material is not included in the article's Creative Commons licence and your intended use is not permitted by statutory regulation or exceeds the permitted use, you will need to obtain permission directly from the copyright holder. To view a copy of this licence, visit http://creativecommons.org/licenses/by/4.0/.

\section{References}

Arpaly N, Schroeder T (2014) In praise of desire. Oxford University Press, Oxford

Balderrama FE, Rodríguez R (2006) Decade of Betrayal: Mexican Repatriation in the 1930s, Revised. University of New Mexico Press, Albuquerque

Butt D (2013) The polluter pays? Backward-looking principles of intergenerational justice and the environment. Spheres of Global Justice. Springer, Dordrecht, pp 757-774

Calhoun C (1989) Responsibility and Reproach. Ethics 99:389-406

Darby D, Branscombe N (2014) Beyond the Sins of the Fathers. Midwest Studies In Philosophy XXXVIII: 121-37

FitzPatrick WJ (2008) Moral responsibility and normative ignorance: answering a new skeptical challenge. Ethics 118:589-613

Gomez A, Morin R, Bologna G, Zhu A (2019) "I thought she was going to die": Parents separated from children after Mississippi ICE raids. USA Today

Goodman A (2020) The deportation machine. Princeton University Press, Princeton

Haines E (2020) 'This invokes a history of terror': Central Park incident between white woman and black man is part of a fraught legacy. Washington Post

Harman E (2011) Does moral ignorance exculpate? Ratio 24:443-468

Hiller A (2011) Climate change and individual responsibility. Monist 94:349-368

Kutz C (2000) Complicity. Cambridge University Press, Cambridge

Lawson B (2013) Individual complicity in collective wrongdoing. Ethical Theory Moral Pract 16:227-243

List C, Pettit P (2011) Group agency. Oxford University Press, Oxford

Lu C (2017) Justice and reconciliation in world politics. Cambridge University Press, Cambridge

Mason E (2015) Moral ignorance and blameworthiness. Philos Stud 172:3037-3057

McGary H (1999) Race and social justice. Blackwell, Malden

Medina J (2013) The epistemology of resistance. Oxford University Press, Oxford

Mills C (2017) White ignorance. Black rights/white wrongs: the critique of racial liberalism. Oxford University Press, Oxford, pp 49-71

Moody-Adams MM (1997) Fieldwork in familiar places: Morality, culture, and philosophy. Harvard University Press, Cambridge, MA

Nuti A (2018) Temporary labour migration within the EU as structural injustice. Ethics Int Aff 32:203-225

Nuti A (2019) Injustice and the reproduction of history: structural inequalities. Cambridge University Press, Cambridge, Gender and Redress

Parfit D (1984) Reasons and Persons. Clarendon Press, Oxford

Prevention of Illegal Entry of Aliens. (1952) Washington D.C. https://www.govinfo.gov/content/pkg/GPOCRECB-1952-pt1/pdf/GPO-CRECB-1952-pt1-18-1.pdf

Religion (2020) Gallup Historical Trends. https://news.gallup.com/poll/1690/religion.aspx

Rosen G (2003) Culpability and Ignorance. Proc Aristot Soc 103:61-84

Rosen G (2004) Skepticism about moral responsibility. Philosophical Perspectives 18:295-313

Sangiovanni A (2018) structural injustice and individual responsibility. J Soc Philos 49:461-483 
Sher G (2009) Who knew? Oxford University Press, Oxford, Responsibility without Awareness

Shklar J (1998) The liberalism of fear. Political thought and political thinkers. University of Chicago Press, Chicago, pp 3-21

Thompson DF (1987) Political ethics and public office. Harvard University Press, Cambridge

Office of the Historian and Office of the Clerk, U.S. House of Representatives (2013) Hispanic Americans in congress, 1822-2012. U.S. Government Printing Office, Washington D.C.

Walzer M (1973) Political action: the problem of dirty hands. Philos Public Aff 2:160-180

Young IM (2011) Responsibility for justice. Oxford University Press, Oxford

Zoller D (2015) Moral responsibility for distant collective harms. Ethical Theory Moral Pract 18:995-1010

Publisher's Note Springer Nature remains neutral with regard to jurisdictional claims in published maps and institutional affiliations. 